MATHEMATICA, 60 (83), $\mathrm{N}^{\circ}$ 2, 2018, pp. 166-176

\title{
NEW INTEGRAL INEQUALITIES FOR $(r, \alpha)$-FRACTIONAL MOMENTS OF CONTINUOUS RANDOM VARIABLES
}

\author{
MOHAMED HOUAS, ZOUBIR DAHMANI, and MEHMET ZEKI SARIKAYA
}

\begin{abstract}
In this paper, we establish new integral inequalities for continuous random variables. By introducing new concepts on fractional moments of continuous random variables, we generalize some interesting results of P. Kumar. Other fractional integral results are also presented.
\end{abstract}

MSC 2010. 26D15, 26A33, 60E15.

Key words. Integral inequalities, Riemann-Liouville integral, random variable, fractional dispersion, fractional variance, fractional moment.

\section{REFERENCES}

[1] A.M. Acu, F. Sofonea and C.V. Muraru, Gruss and Ostrowski type inequalities and their applications generalization of Chebyshev inequality, Sci. Stud. Res. Ser. Math. Inform., 23 (2013), 5-14.

[2] G.A. Anastassiou, M.R. Hooshmandasl, A. Ghasemi and F. Moftakharzadeh, Montgomery identities for fractional integrals and related fractional inequalities, JIPAM, 10 (2009), 1-6.

[3] G.A. Anastassiou, Fractional differentiation inequalities, Springer-Verlag, New York, 2009.

[4] N.S. Barnett, P. Cerone, S.S. Dragomir and J. Roumeliotis, Some inequalities for the expectation and variance of a random variable whose pdf is n-time differentiable, JIPAM, 1 (2000), 1-29.

[5] N.S. Barnett, P. Cerone, S.S. Dragomir and J. Roumeliotis, Some inequalities for the dispersion of a random variable whose pdf is defined on a finite interval, JIPAM, 2 (2001), 1-18.

[6] S. Belarbi and Z. Dahmani, On some new fractional integral inequalities, JIPAM, 10 (2009), 1-12.

[7] P.L. Chebyshev, Sur les expressions approximatives des integrales definis par les autres prises entre les memes limite, Proc. Math. Soc. Charkov, 2 (1882), 93-98.

[8] Z. Dahmani, New applications of fractional calculus on probabilistic random variables, Acta Math. Univ. Comenian. (N.S.), 86 (2017), 299-307.

[9] Z. Dahmani and L. Tabharit, On weighted Gruss type inequalities via fractional integrals, JARPM (IASR), 2 (2010), 31-38.

[10] Z. Dahmani, On Minkowski and Hermite-Hadamard integral inequalities via fractional integration, Ann. Funct. Anal., 1 (2010), 51-58.

[11] Z. Dahmani, L. Tabharit and S. Taf, New generalisations of Gruss inequality using Riemann-Liouville fractional integrals, Bull. Math. Anal. Appl., 2 (2010), 93-99.

[12] Z. Dahmani, Fractional integral inequalities for continuous random variables, Malaya J. Mat., 2 (2014), 172-179.

DOI: $10.24193 /$ mathcluj.2018.2.08 
[13] Z. Dahmani, A.E. Bouziane, M. Houas and M.Z. Sarikaya, New W-weighted concepts for continuous random variables with applications, Note Mat., 37 (2017), 23-40.

[14] S.S. Dragomir, A generalization of Gruss inequality in inner product spaces and applications, J. Math. Anal. Appl., 237 (1999), 74-82.

[15] P. Kumar, Moment inequalities of a random variable defined over a finite interval, JIPAM, 3 (2002), 1-24.

[16] P. Kumar, Inequalities involving moments of a continuous random variable defined over a finite interval, Computers and Mathematics with Applications, 48 (2004), 257-273.

[17] Y. Miao and G. Yang, A note on the upper bounds for the dispersion, JIPAM, 8 (2007), $1-13$.

[18] D.C. Mitrinovic, J.E. Pecaric and A.M. Fink, Classical and new inequalities in analysis, Kluwer Academic Publishers, Dordrecht, 1993.

[19] T.F. Mori, Sharp inequalities between centered moments, JIPAM, 10 (2009), 1-19.

[20] M. Niezgoda, New bounds for moments of continuous random variables, Computers and Mathematics with Applications, 60 (2004), 3130-3138.

[21] B.G. Pachpatte, On multidimensional Gruss type integral inequalities, JIPAM, 3 (2002), $1-15$.

[22] R. Sharma, S. Devi, G. Kapoor, S. Ram and N.S. Barnett, A brief note on some bounds connecting lower order moments for random variables defined on a finite interval, International Journal of Theoretical \& Applied Sciences, 1 (2009), 83-85.

[23] M.Z. Sarikaya and H. Yaldiz, Note on the Ostrowski type inequalities for fractional integrals, Vietnam J. Math., 41 (2013), 2-6.

[24] M.Z. Sarikaya and H. Yaldiz, New generalization fractional inequalities of OstrowskiGruss type, Lobachevskii J. Math., 34 (2013), 326-331.

[25] M.Z. Sarikaya, H. Yaldiz and N. Basak, New fractional inequalities of Ostrowski-Grüss type, Le Matematiche, 69 (2014), 227-235.

[26] M.Z. Sarikaya, N. Aktan and H. Yildirim, On weighted Chebyshev-Gruss like inequalities on time scales, J. Math. Inequal., 2 (2008), 185-195.

[27] M.Z. Sarikatya and H. Ogunmez, New fractional inequalities of Ostrowski-Gruss type, Abstr. Appl. Anal., 2012 (2012), Article 428983, 1-10.

Received December 16, 2017

Accepted March 24, 2018
University of Khemis Miliana

Laboratory FIMA, UDBKM

Algeria

E-mail: houasmed@yahoo.fr

University of Mostaganem

Laboratory LPAM, UMAB

Algeria

E-mail: zzdahmani@yahoo.fr

Düzce University

Department of Mathematics

Faculty of Science and Arts,

Düzce, Turkey

E-mail: sarikaya@aku.edu.tr 